\title{
The Utilization of Dental Hygienists in Oral Healthcare Exchanges between the South and North Korea
}

\author{
Eunsuk Ahn ${ }^{1}$, Ji-Hyoung Han², Kyung-Hee Kang ${ }^{3}$, Young-Eun Jang ${ }^{4}$, Ki-Ha Jeon ${ }^{5}$, and \\ Jeong-Ran Park ${ }^{4, \dagger}$ \\ 'Department of Dental Hygiene, Daejeon Institute of Science and Technology, Daejeon 35408, ${ }^{2}$ Department \\ of Dental Hygiene, Suwon Science College, Hwaseong 18516, ${ }^{3}$ Department of Dental Hygiene, College of \\ Medical Science, Konyang University, Daejeon 32992, ${ }^{4}$ Department of Dental Hygiene, Baekseok University, \\ Cheonan 31065, ${ }^{5}$ Department of Dental Hygiene, Shinsung University, Dangjin 31801, Korea
}

\begin{abstract}
Background: This study aimed to identify the role of dental hygienists in exchanges between North and South Korea to lower gaps in the level of dental healthcare between the two countries by conducting a Delphi survey with specialists and identifying alternative policies regarding the utilization of dental hygienists in such exchanges.

Methods: Two Delphi surveys were conducted with the participation of nine specialists, and descriptive statistical analyses including mean and standard deviation were performed on the collected data.

Results: Among methods of exchange and cooperation regarding oral healthcare under the current North Korean medical system, the issue considered most urgent was the "establishment of oral healthcare infrastructure." The most important short-term strategy was identified as the "selection and formation of partnerships in the field of inter-Korean oral health exchange and cooperation." The mid-term strategy was identified as the "establishment of cooperation in the dental industry, centered on educational cooperation projects." The long-term strategy included "joint R\&D projects, oral health surveys, and business development." In order to determine how best to use dental hygienists during inter-Korean exchanges and cooperation, the respondents placed urgency on the "establishment of joint cooperation projects for oral health promotion and early examination and the treatment of dental diseases and planning of community research projects" and "the role of oral health education and media development for residents."

Conclusion: Cooperation is necessary regarding the preparation of oral healthcare exchanges that aim to encourage unity between North and South Korea and reduce the gaps between the North and South regarding oral health conditions. Therefore, continuous and reasonable discussions and research are needed regarding the utilization of dental hygienists in such exchanges.
\end{abstract}

Key Words: Dental care, Dental hygienists, North Korea, South Korea

\section{Introduction}

On August 15, 1945, North Korea was established as a socialist nation with the support of the former Soviet Union and accordingly began to implement a free healthcare system. However, this system is merely nominal at present due to a lack of medical resources and insufficient infrastructure, among other factors ${ }^{1,2)}$.

According to "Twelve Unforgettable Crisis Territories" published by the United Nations' Office for the Coordination of Humanitarian Affairs (OCHA) in 2017, 25\% of North Koreans had no access to essential medical services, and 1.7 million children, including infants, were exposed to the risks of contracting fatal diseases ${ }^{3)}$. Further, the security of medicine in North Korea is seriously affected by supply shortages, causing frequent infections.

To date, multiple countries and institutions including South Korea have supported North Korea by providing 
facilities and devices to help recover the country's public healthcare system. However, the support provided to North Korea by private organizations is primarily anecdotal, which is a serious limitation. It is necessary to establish short- and mid-to-long term plans based on practical healthcare problems in North Korea, to provide systemic education and training to healthcare professionals, and to identify strategies regarding the utilization of healthcare resources, rather than anecdotal support ${ }^{4,5)}$.

North Korea's "Law on Healthcare Professionals" defines the training, qualifications, and roles of various types of healthcare professionals, and the North Korean system for dental healthcare professionals differs from that of South Korea. North Korea differentiates between dental doctors, who have graduated from medical schools, semi-dental doctors, and prosthetists. Prosthetists produce dentures and practice prosthodontics, tasks that are carried out by dentists in South Korea. Dental hygienists and dental technicians, which are dental healthcare professionals in South Korea, do not exist in North Korea ${ }^{6}$.

Dental hygienists in South Korea practice integrative dental care including preventive work such as dental care education, tooth sealants, and scaling in addition to work supporting dental care ${ }^{7-9}$. In exchanges between the South and North, the treatment of dental diseases and rehabilitation can mainly be supported by dentists, while dental care education, preventive procedures, and continuous dental health management can be primarily supported by dental hygienists.

Support activities conducted efficiently by dental healthcare professionals will lower the gap in the dental healthcare levels between South and North, contributing to the establishment of a stable system within a short time in the case of the integration of the dental healthcare systems of the two Koreas. Hence, it is necessary to discuss plans to support North Korean dentistry with dental healthcare professionals so as to prepare exchanges between and the integration of the two Koreas.

Therefore, this study aimed to identify the roles of dental hygienists in decreasing the gap in the dental healthcare level between the two Koreas by conducting a Delphi survey with specialists in order to suggest alternative policies regarding the utilization of dental hygienists in exchanges between South and North Korea.

\section{Materials and Methods}

\section{Subjects}

In this study, nine specialists in South and North exchanges and dental healthcare who understood the purposes of the Delphi survey were organized as the panelists. The expert panel consisted of dentists, nurses, and healthcare workers who were engaged in inter-Korean healthcare-related projects or in providing healthcare for North Korean refugees. Written informed consent was obtained from subjects who agreed to participate in the study.

\section{Methods}

Two Delphi surveys were conducted in this study. The first survey included open-ended free description questions, and the second survey included closed questions that were created based on the results of the first survey. To compose the first questionnaire, a draft questionnaire was prepared using a focus group created by the researchers. A pilot study was conducted to identify any ambiguous or unclear questions, after which the first questionnaire was corrected. The second Delphi survey questionnaire was structured so that respondents could refer to the results of the first survey by presenting expert opinions from the first survey in terms of frequency and median. The contents of the Delphi survey were designed to collect respondents' opinions regarding dental healthcare exchanges between South and North, integrative plans, and the utilization of dental hygienists. The opinions presented in the second Delphi survey were classified into five areas including areas of interest and requirements for North Korean dental healthcare; types of urgent dental care for North Koreans and their importance; methods of dental healthcare exchanges under the North Korean medical system; short-, mid-, and long-term strategies of dental healthcare in case of exchanges; and plans for the utilization of dental hygienists in such exchanges.

In the second Delphi survey, urgency and importance were measured on a three- or four-point scale, checking priorities, and descriptive statistical analysis was performed 
on the collected data including the identification of mean and standard deviation by item.

\section{Results}

\section{North Koreans' interest in and demand for oral health}

Table 1 shows the degree to which experts ranked North Koreans' interest in and demand for oral health. "Demand for the prevention and treatment of dental caries in children" was the highest at 3.44, and "demand for preservation, prosthetic treatment, and implant treatment" and "demand for periodontal disease treatment in adults" were 3.33 .

\section{Urgency and importance of dental treatment for North Koreans}

The urgency and importance of dental treatment for
North Koreans is as follows. The urgency was 2.89 for "caries treatment," and 2.72 for "oral examination" and "gingival treatment," respectively. The coefficient of variation decreased from 0.00 to 0.44 in the first round to 0.00 to 0.35 in the second round. The importance of "oral examination" was 2.94, "caries treatment" was 2.83 , and "gingival treatment" was 2.61, and "preventive treatment" and "root canal treatment" were 2.56. The coefficient of variation decreased from 0.12 to 0.35 in the first round to 0.00 to 0.30 in the second round, and both urgency and importance showed more converging opinions in the second order than in the first order (Table 2).

\section{Urgent issues in the area of oral healthcare for exchange and cooperation}

Among the methods of exchange and cooperation of oral healthcare that should be provided to North Korean residents under the current North Korean medical system,

Table 1. North Koreans' Interest and Demand for Oral Health

\begin{tabular}{lcccccc}
\hline \multicolumn{1}{c}{ Contents } & $\mathrm{n}$ & Mean & SD & Min & Max & CV \\
\hline Demand for preservation, prosthetic treatment, and implant treatment & 9 & 3.33 & 0.50 & 3.00 & 4.00 & 0.15 \\
Demand for periodontal disease treatment in adults & 9 & 3.33 & 0.50 & 3.00 & 4.00 & 0.15 \\
Demand for the prevention and treatment of dental caries in children & 9 & 3.44 & 0.73 & 2.00 & 4.00 & 0.21 \\
$\begin{array}{l}\text { Demand for preventive treatment such as scaling for some groups with } \\
\text { high socioeconomic status }\end{array}$ & 9 & 2.56 & 0.73 & 1.00 & 3.00 & 0.28 \\
$\begin{array}{l}\text { Demand for oral health promotion such as brushing and oral health } \\
\text { education }\end{array}$ & 9 & 3.11 & 0.33 & 3.00 & 4.00 & 0.10 \\
\hline
\end{tabular}

SD: standard deviation, Min: minimum, Max: maximum, CV: coefficient of variation.

Table 2. North Koreans' Urgency and Importance by Dental Treatment

\begin{tabular}{|c|c|c|c|c|c|c|c|c|c|}
\hline \multirow{2}{*}{ Treatment } & \multirow{2}{*}{$\mathrm{n}$} & \multicolumn{2}{|c|}{ Urgency } & \multirow{2}{*}{1 round } & \multirow{2}{*}{ 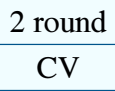 } & \multicolumn{2}{|c|}{ Importance } & \multirow{2}{*}{$\begin{array}{c}1 \text { round } \\
\mathrm{CV}\end{array}$} & \multirow{2}{*}{$\frac{2 \text { round }}{\mathrm{CV}}$} \\
\hline & & Mean & SD & & & Mean & $\mathrm{SD}$ & & \\
\hline Oral examination & 18 & 2.72 & 0.57 & 0.19 & 0.24 & 2.94 & 0.24 & 0.12 & 0.00 \\
\hline $\begin{array}{l}\text { Preventive treatment (sealant, } \\
\text { fluoride application, etc.) }\end{array}$ & 18 & 2.22 & 0.81 & 0.44 & 0.30 & 2.56 & 0.51 & 0.21 & 0.21 \\
\hline Caries treatment & 18 & 2.89 & 0.32 & 0.16 & 0.00 & 2.83 & 0.38 & 0.16 & 0.12 \\
\hline Gingival treatment & 18 & 2.72 & 0.57 & 0.28 & 0.12 & 2.61 & 0.50 & 0.21 & 0.19 \\
\hline Root canal treatment & 18 & 2.56 & 0.51 & 0.22 & 0.19 & 2.56 & 0.62 & 0.30 & 0.19 \\
\hline Extraction & 18 & 2.17 & 0.71 & 0.37 & 0.30 & 2.22 & 0.65 & 0.30 & 0.30 \\
\hline Surgical treatment & 18 & 2.00 & 0.77 & 0.43 & 0.35 & 2.06 & 0.54 & 0.35 & 0.16 \\
\hline Prosthetic treatment & 18 & 2.56 & 0.62 & 0.30 & 0.16 & 2.56 & 0.62 & 0.30 & 0.19 \\
\hline $\begin{array}{l}\text { The other (orthodontic } \\
\text { treatment etc.) }\end{array}$ & 16 & 1.06 & 0.25 & 0.00 & 0.30 & 1.06 & 0.25 & 0.00 & 0.30 \\
\hline
\end{tabular}

SD: standard deviation, CV: coefficient of variation. 
Table 3. Among the Methods of Exchange and Cooperation, Urgent Issues in the Area of ral Healthcare

\begin{tabular}{|c|c|c|c|c|c|}
\hline Contents & $\mathrm{n}$ & Mean & SD & Min & Max \\
\hline Oral healthcare support and cooperation & 18 & 4.50 & 2.46 & 1.00 & 8.00 \\
\hline Establishment of oral healthcare infrastructure & 18 & 3.39 & 2.75 & 1.00 & 9.00 \\
\hline Oral health and oral disease survey & 18 & 3.56 & 2.28 & 1.00 & 7.00 \\
\hline Exchange on the provision of oral health medical facilities and services in North Korea & 18 & 3.67 & 1.68 & 1.00 & 7.00 \\
\hline Inter-Korean oral health medical personnel exchange & 18 & 3.89 & 1.49 & 1.00 & 7.00 \\
\hline Oral healthcare personnel education and training support & 18 & 4.72 & 1.96 & 1.00 & 8.00 \\
\hline South and North Korea oral healthcare R\&D & 18 & 5.83 & 1.62 & 2.00 & 8.00 \\
\hline Oral health education for North Koreans & 18 & 6.78 & 1.93 & 2.00 & 8.00 \\
\hline
\end{tabular}

SD: standard deviation, Min: minimum, Max: maximum.

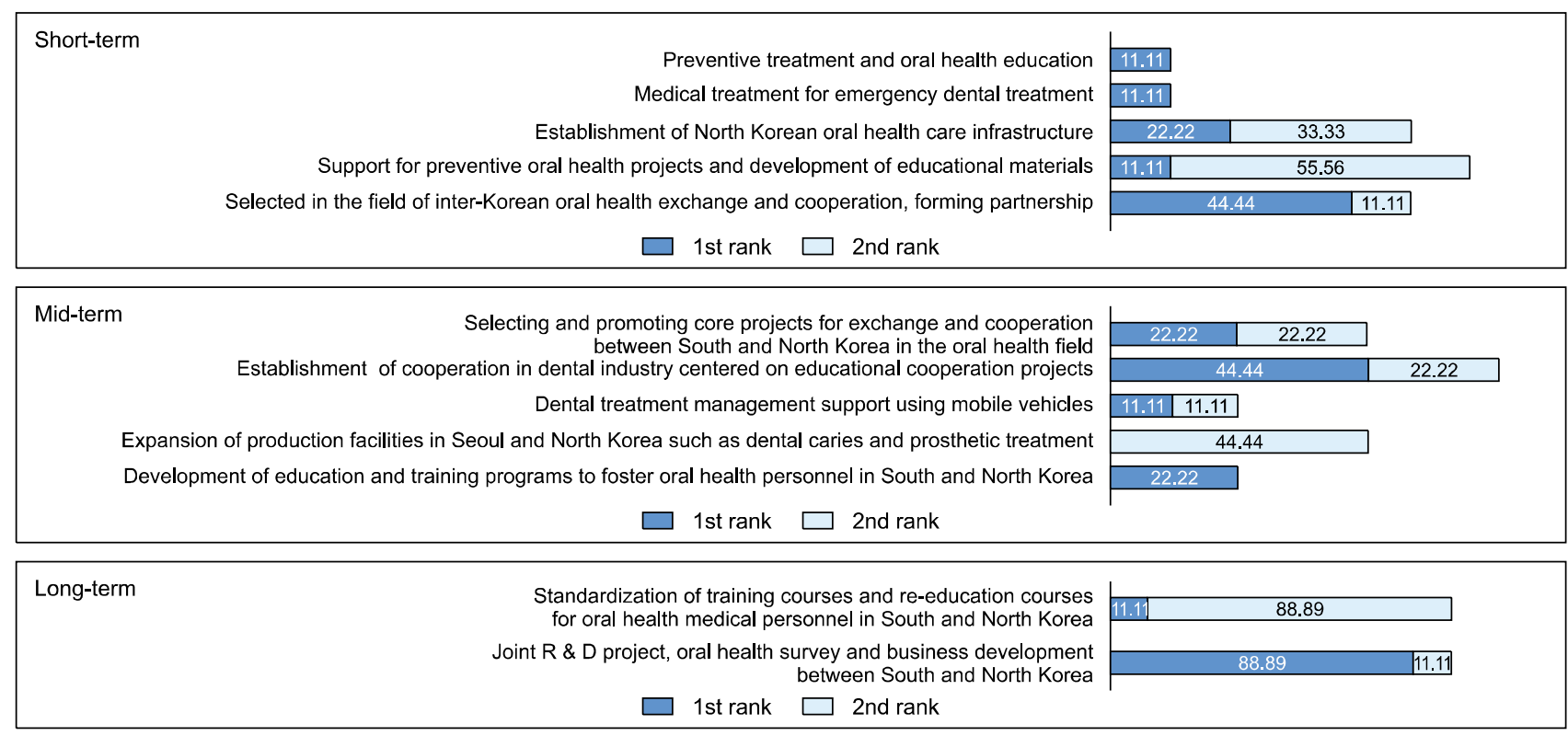

Fig. 1. Short-term, mid-term, and long-term oral healthcare projects that must be promoted during exchange and cooperation between South and North Korea.

several issues were considered urgent (Table 3). The "establishment of oral healthcare infrastructure (establishment of implant production plants, establishment toothpaste production plants)" was the top priority, followed by "oral health and oral disease survey." As a result of the mean for each item, the "oral health education for North Koreans" was highest, followed by the "South and North Korea oral healthcare R\&D". After that, the "oral healthcare personnel education and training support" and the "oral healthcare support and cooperation" were high.

\section{Short-term, mid-term, and long-term oral healthcare projects to be promoted during exchange and cooperation between South and North Korea}

Fig. 1 shows the results of a survey of oral healthcare projects that should be promoted during inter-Korean exchange and cooperation divided into short-, mid-, and long-term strategies. Among the short-term strategies, the top rankings were "selection and partnership formation in the field of inter-Korean oral health exchange and cooperation," and "building infrastructure for oral health management in North Korea." Among the mid-term strategies were the "establishment of cooperation in the 
Table 4. How to Use Dental Hygienists in Inter-Korean Exchange and Cooperation

\begin{tabular}{|c|c|c|c|c|c|c|c|}
\hline \multirow{2}{*}{ Contents } & \multirow{2}{*}{$\mathrm{n}$} & \multicolumn{3}{|c|}{ Urgency } & \multicolumn{3}{|c|}{ Importance } \\
\hline & & Mean & SD & $\mathrm{CV}$ & Mean & SD & CV \\
\hline $\begin{array}{l}\text { Establishing an independent exchange point of contact between } \\
\text { North and South Korea, centered on the Korean Dental Hygienist } \\
\text { Association }\end{array}$ & 9 & 2.11 & 0.78 & 0.37 & 2.44 & 0.53 & 0.22 \\
\hline $\begin{array}{l}\text { Identify the current status of the professional manpower system in } \\
\text { the area of ental hygienists among health workers in North Korea } \\
\text { and prepare plans for retraining }\end{array}$ & 9 & 2.33 & 0.87 & 0.37 & 2.44 & 0.73 & 0.30 \\
\hline $\begin{array}{l}\text { Establishment of joint cooperation project for oral health promotion } \\
\text { and early examination and treatment of dental diseases for North } \\
\text { Korean residents and planning of community research project }\end{array}$ & 9 & 2.56 & 0.73 & 0.28 & 2.56 & 0.53 & 0.21 \\
\hline $\begin{array}{l}\text { Support for dental hygienist education facilities and training system } \\
\text { in North Korea }\end{array}$ & 9 & 2.00 & 0.50 & 0.25 & 2.44 & 0.53 & 0.22 \\
\hline $\begin{array}{l}\text { The role of oral health education and media development for North } \\
\text { Korean residents' }\end{array}$ & 9 & 2.11 & 0.60 & 0.28 & 2.56 & 0.53 & 0.21 \\
\hline
\end{tabular}

SD: standard deviation, CV: coefficient of variation.

dental industry, centered on educational cooperation projects," "development of education and training programs to foster oral health personnel in South and North Korea," and "selecting and promoting core projects for exchange and cooperation between South and North Korea in the oral health field." The number one long-term strategy was "joint R\&D project, oral health surveys, and business development between South and North Korea."

\section{The use of dental hygienists in inter-Korean exchanges and cooperation}

In order to determine how best to use dental hygienists in the oral healthcare field during inter-Korean exchanges and cooperation, a survey was conducted to classify tasks by urgency and importance (Table 4). The urgency was highest at 2.56 for the "establishment of joint cooperation projects for oral health promotion and early examination and the treatment of dental diseases for North Korean residents and planning of community research projects". The "identify the current status of the professional manpower system in the area of ental hygienists among health workers in North Korea and prepare plans for retraining" was 2.33. The coefficient of variation was less than 0.5 in all subscales and showed stable results. The importance was 2.56 for "establishment of joint cooperation projects for oral health promotion and early examination and treatment of dental diseases for North
Korean residents and planning of community research project" and "the role of oral health education and media development for North Korean residents," respectively. The coefficient of variation ranged from 0.21 to 0.30 , showing a relatively stable result.

\section{Discussion}

In North Korea, as there are no "dental hygienists," there are "prosthetists"; however, there are significantly fewer prosthetists in North Korea than there are dental hygienists in South Korea ${ }^{6}$. It is thus expected that dental health preventive treatment is insufficient in North Korea's dental health medical system.

By examining experts' perspectives regarding North Koreans' degree of interest in and demand for dental health, we found that the demand for the prevention and treatment of dental caries in children was the highest. This may be due to the lack of education and treatment regarding the importance of dental health or habit formation for children in the collapsed medical environment of North Korea. In the expert survey, dental treatments that should be urgently provided to North Korean defectors were identified as "caries treatment" and "gum treatment," and "dental examination" and "caries treatment" were identified as most important. Thus, when dental hygienists conduct dental health promotion education 
for exchanges, cooperation, and integration between North and South, the concept and importance of "caries treatment" and "gum treatment" should be highlighted. When dental health promotion programs are planned during such exchanges, it is necessary to prioritize "oral examination" and "caries treatment." These results are similar to those of previous studies that have found prominent tooth decay issues in North Korea defectors and have proposed oral health examination programs to continue to manage such issues ${ }^{10)}$.

"Building a dental health medical infrastructure" emerged as the most urgent issue for medical exchanges and cooperation between the Koreas, and this can be attributed to the lack of medical facilities and bases in North Korean society due to the collapse of the country's economy, which has also been found in preceding studies ${ }^{11)}$. "Oral health education for North Korean residents" and "South and North Korea dental health medical R\&D" were identified as necessary methods of exchange and cooperation for the North Korean medical system. The promotion of R\&D can be expected to reduce the gap in oral health between South and North Korea and minimize unification costs after integration.

The results of this study can be used to provide the following suggestions for the use of dental hygienists in the promotion of integration and cooperation in the dental health medical field in South and North Korea.

First, in the period of exchange and cooperation, focus should be placed on nurturing professionals who can provide primary dental health treatments, particularly through training dental hygienists. In situations in which the dental medical resources in North Korea are scarce, the most efficient method for providing services is prevention using a "dental team," the promotion of dental health, and the provision of dental treatment. The World Health Organization's professional committee for dental auxiliary personnel recommends the maximum use of dental auxiliary personnel such as dental hygienists and dental technicians in order to provide effective dental services using limited resources ${ }^{12)}$. In particular, regarding the training period and costs, the establishment of public dental health service infrastructure and the expansion of the social safety net through the promotion of dental health and prevention centered on dental hygienists, who are more accessible than dentists, are thought to be the most effective policy tools.

After integration, dental facilities and infrastructure should be established in order to provide stable oral healthcare services in North Korea. To this end, dental hygienists must establish long-term governance for oral health management and establish standardized oral health promotion policies. Dental hygienist should take part in the planning of oral health programs. North Korea has a doctor's zone system with one or two quasi-doctors positioned at each clinic ${ }^{11)}$, and dental hygienists should be deployed to these clinics to promote dental health. Further, dental hygienists should be responsible for public oral health projects such as oral health education, dental health promotion, and preventive measures.

In the future, if South and North Korean exchanges and cooperation continue and the countries are integrated, large-scale political and economic changes will likely occur due to changes in social security and the healthcare system. In particular, gaps in the health level of South and North Korea act as a basic and important barrier to inclusion, and the budget that needs to be invested to close this health gap could be astronomical ${ }^{13-15)}$, so continuous research and rational discussions are necessary.

In this study, an application plan for dental hygienist was proposed in a larger framework. There are some limitations in making specific proposals due to the political characteristics of South and North Korea, but this study is meaningful in that it presents a new direction of dental health policy in consideration of the future integration of South and North Korea. As described above, education and systems related to dental health manpower in South Korea and North Korea show considerable differences, which is expected to cause difficulties in the integration process. Therefore, follow-up research and discussion on continuous and rational integration plans are necessary.

\section{Notes}

\section{Conflict of interest}

No potential conflict of interest relevant to this article was reported. 


\section{Ethical approval}

This study was approved by the Institutional Review Board of Baekseok University (BUIRB-202001-HR-024).

\section{Author contributions}

Conceptualization: Eunsuk Ahn, Ji-Hyoung Han, Kyung-Hee Kang, Young-Eun Jang, Ki-Ha Jeon, and Jeong-Ran Park. Data acquisition: Eunsuk Ahn, Ji-Hyoung Han, Kyung-Hee Kang, Young-Eun Jang, Ki-Ha Jeon, and Jeong-Ran Park. Formal analysis: Eunsuk Ahn and Ji-Hyoung Han. Supervision: Ji-Hyoung Han and Jeong-Ran Park. Writing-original draft: Ji-Hyoung Han, Kyung-Hee Kang, Ki-Ha Jeon, and Young-Eun Jang. Writing-review \& editing: Ji-Hyoung Han and Jeong-Ran Park.

\section{ORCID}

Eunsuk Ahn, https://orcid.org/0000-0002-9404-4826

Ji-Hyoung Han, https://orcid.org/0000-0003-1613-2879

Kyung-Hee Kang, https://orcid.org/0000-0003-3439-1049

Young-Eun Jang, https://orcid.org/0000-0001-8705-3364

Ki-Ha Jeon, https://orcid.org/0000-0002-6588-0075

Jeong-Ran Park, https://orcid.org/0000-0001-7386-4967

\section{Acknowledgements}

This study was supported by research fund from, Oral Health Coalition of South and North Korea, 2020.

\section{References}

1. Lee MJ, Kim HN, Cho DB, Kim SY: Overview of healthcare system in North Korea. J Korean Med Assoc 56: 358-367, 2013. https://doi.org/10.5124/jkma.2013.56.5.358

2. Kim JH, Jung YM, Choi HS, et al.: An estimation of supply and demand for primary healthcare nursing workforce in the North Korean region after Korean reunification. J Korean Acad Nurs Adm 25: 353-361, 2019. https://doi.org/10.11111/jkana.2019.25.4.353

3. Retrieved January 2, 2021, from https://reliefweb.int/report/ world/12-forgotten-crises-remember.pdf(2017).

4. Han DH, Shin TJ, Myoung H, Lee SP, Kim CC: Current status and prospects of oral health services exchange from
South and North Korea through nongovernmental organizations. J Korean Dent Assoc 53: 705-711, 2015.

5. Kyung KS: A proposal for the development of personnel in the DPRK for public health and medicine. Korean Med Educ Rev 18: 21-25, 2016. https://doi.org/10.17496/KMER.2016.18.1.21

6. Shin TJ, Han DH, Jin BH, Kim TI, Lee JI, Kim C: A study on the North Korea's dentistry education system and its implication on the direction for integration of South and North Korea's dentistry education. J Korean Dent Assoc 53: 726-731, 2015.

7. Kim SM, Ahn E, Hwang SJ, Jeong SJ, Kim BR, Han JH: Korean dental hygienists' job description based on systematic review. J Dent Hyg Sci 20: 187-199, 2020. https://doi.org/10.17135/jdhs.2020.20.4.187

8. Kwon JY, Lee SY: Relationship of between task performance, job satisfaction, and organizational contribution of dental hygienists. J Dent Hyg Sci 16: 302-309, 2016. https://doi.org/10.17135/jdhs.2016.16.4.302

9. Hyeong JH, Jang YJ, Ju OJ: Dental hygienists' work cognition and demand for related legislation. J Korean Soc Dent Hyg 18: 693-705, 2018. https://doi.org/10.13065/jksdh.20180060

10. Kang YS, Ha YM, Eun Y: Health status and healthpromoting lifestyle profile II of North Korean immigrants. J Korean Acad Community Health Nurs 23: 231-243, 2012.

11. Park SM, Lee HW: Current status of healthcare and effective health aid strategies in North Korea. J Korean Med Assoc 56: 368-374, 2013.

https://doi.org/10.5124/jkma.2013.56.5.368

12. Jeon KH, Lee SY: Evaluation of customized oral health promotion program for North Korean defector. J Korean Acad Oral Health 42: 109-117, 2018. https://doi.org/10.11149/jkaoh.2018.42.4.109

13. Retrieved January 2, 2021, from https://apps.who.int/iris/ handle/10665/87354.pdf(1959).

14. Lee SB: The health care system and outcomes of North Korea: a comparative analysis on the international level. Korean J Polit Sci 17: 79-97, 2010.

15. Kim JM, Park TK: A case study on the institutional and social integration after German unification. JIAS 27: 91-117, 2018. 